\title{
“Señas de identidad": Desarraigo alienante y revisión cultural
}

\section{Ceferino PUEBLA PEDROSA}

\section{INTRODUCCIÓN}

Señas de identidad, publicada en México en 1966 por Juan Goytisolo, es una novela "experimental" que continuó el camino abierto por Tiempo de silencio, de Luis Martín-Santos en 1962. Superando la novela del realismo social, los jóvenes novelistas mantuvieron la crítica social, pero la técnica, el enfoque y el léxico son muy innovadores y rompen los moldes de la novelística anterior. En la narrativa de Goytisolo Señas de identidad marca un cambio y una ruptura con sus obras anteriores. Abandona la crítica de la burguesía y hace una autorreflexión y una revisión socio-cultural de España.

Señas de identidad es una narración retrospectiva de estilo autobiográfico en la que el protagonista intenta reencontrar sus raíces, recordando sus lazos familiares, amistades de juventud, su exilio en París y sus viajes por varios países. A la vez que intenta recuperar su identidad, el protagonista revisa la realidad española de la guerra civil y la posguerra, y hace una crítica dura de la sociedad franquista y de la alienación del pueblo español al comienzo del despegue económico de los años 1960. Como novela experimental, la técnica de esta obra es excelente: saltos temporales con cambios bruscos de escenario, narraciones en las 3 personas gramaticales, monólogos interiores, párrafos sin puntuación, informes y testimonios, diálogos en francés, etc., todo está integrado en el texto. Narrador autobiográfico desdoblado, desorden cronológico y desmitificación revisionista son las características de esta obra que combina el enfoque documental con la crítica subjetiva. 
En este artículo voy a analizar el desarraigo y alienación del protagonista Álvaro Mendiola, como símbolo de una época de la posguerra española. También veré el intento desmitificador de valores típicos de la sociedad española, encaminado a una renovación cultural y una nueva narrativa.

\section{ELEMENTOS AUTOBIOGRÁFICOS (ÁLVARO = GOYTISOLO)}

\subsection{Argumento y estructura literaria}

Señas de identidad es una novela de protagonista individual, Álvaro Mendiola, que ha vuelto a Barcelona en 1963 con su mujer Dolores. Álvaro está exiliado voluntariamente en París desde 1952 y ha venido unos días a su casa natal porque está enfermo de corazón, se siente cansado y desarraigado. Aquí, junto con Dolores y unos antiguos amigos de universidad, recuerda a su familia y su niñez (cap.I), asiste al entierro del profesor Ayuso y recuerda su época de universitario (cap.II), diversos episodios de la guerra civil en Yeste, Albacete, entremezclados con su frustrada filmación de un documental en 1958 (cap.III), su estancia en París simultáneamente con la detención y destierro de su amigo Antonio (cap.IV), actividades fracasadas contra el régimen franquista en París y Barcelona (cap.V), su encuentro, amores y viajes con Dolores (cap.VI), los cambios de España en los años 60, emigrantes, y el testimonio de un obrero catalán (cap.VII); finalmente Álvaro busca sus raíces en Barcelona, se siente frustrado y decide salir de España (cap.VIII).

Los 8 capítulos no siguen un orden cronológico y dentro de cada capítulo hay un número variable de secuencias separadas por un espacio en blanco. Dichas secuencias tienen un tiempo distinto y a veces narradores diversos. Generalmente en esta novela se usa la segunda persona narrativa (tú autorreflexivo) cuando el protagonista cuenta recuerdos personales o actividades vividas por él mismo. Es un desdoblamiento del narrador autobiográfico, distinto gramaticalmente del autor omnisciente. La primera persona (yo) se usa para testimonios de otros personajes distintos del protagonista. La primera persona 
plural (nosotros) representa la propaganda oficial, las fuerzas del orden, o las "Voces", es decir, los fantasmas históricos colectivos contra los que se rebela Álvaro. La tercera persona (él, ellos) es simplemente narrativa, representa a Álvaro o a otros seres pasados o actuales. En esta novela el "tú autorreflexivo" predomina en la narración; tiene un valor especial y un sentido autobiográfico, como dice José Ortega: "El predominio de la persona "tú" como reflejo del "yo", el cual se convierte en objeto de autoanálisis, pone en evidencia la preocupación central del personaje de esta novela: la identidad...El "tú" acerca al personaje y forma parte del proceso de incorporación activo del lector en la acción, además de funcionar como contrapunto dialéctico entre "Ellos" y el autor. "Tú" es la conciencia del protagonista con quien el narrador se identifica"(1).

Referente al tiempo narrativo, Señas de identidad abarca un período muy breve: 4 ó 5 días de agosto de 1963. Desde ese punto temporal (que el narrador nos recuerda con frecuencia), Álvaro Mendiola, nacido en 1931, rememora experiencias y sucesos que duraron muchos años: su niñez en Barcelona en los años 30, la guerra civil (1936-1939), su época de colegial y universitario (años 40-50), su exilio en París y sus viajes por Europa, Cuba y sur de España (años 50-60). El tiempo histórico está muy desordenado en la narración y a veces es difícil captar el momento exacto en que se desarrolla la acción. Esta novela tiene una enorme reducción temporal y con frecuencia hay simultaneidad narrativa e irrupción del tiempo real en el tiempo narrativo. La época que describe es la inmediatamente anterior a la guerra civil, la guerra y la posguerra con sus horrores, represalias e injusticias. El padre de Álvaro fue fusilado por los milicianos rojos en Yeste, Albacete, en 1936. Su tío Lucas fue también asesinado por los anarquistas, y su primo Sergio fue llevado por fuerza al frente republicano y nunca más regresó. En el capítulo III cuenta también una revuelta de campesinos y leñadores en Yeste; invadieron los bosques de un cacique y fueron después asesinados en un enfrentamiento con la guardia civil. También describe la opresión política (antiestudiantil, sobre todo) y la penuria 
socio-cultural de los años 50, la emigración masiva a las ciudades grandes españolas y a varios países de Europa; y finalmente la afluencia del turismo (Goytisolo lo critica) y el comienzo de la recuperación económica de los años 60.

El espacio narrativo es también muy variado y cambia en muchas secuencias. La novela comienza con la familia de Álvaro en Barcelona y termina también en esa ciudad que Álvaro contempla desde Montjuich. Hay muchos escenarios diferentes en España, Francia, Suiza, Italia y otros países, incluso Cuba, donde había vivido la familia de los abuelos de Álvaro. En Señas de identidad hay un ambiente internacional, muy amplio, que muestra el conocimiento que Goytisolo tiene de muchos países. Pero en esta novela el espacio vital no ejerce una relación tan condicionante en la actividad de los personajes, como ocurría en las novelas del realismo social. Aquí más que el lugar concreto son las circunstancias socio-culturales y la historia del país lo que realmente influye en la gente de España: "Por espacio de tres años un vendaval de locura había soplado sobre la piel de toro, completando la obra destructora emprendida siglo a siglo, con tesón y paciencia, por tus antepasados ilustres... habían procedido con orden y minuciosidad a la poda cruel e inexorable de sí mismos, arruinando, por turno, el comercio, la industria, la ciencia, las artes... pensabas en Ayuso y tu padre, en los muertos inútiles del 36 y del 39, en la amarga generación de los tuyos, condenada a envejecer sin juventud ni responsabilidades”(2).

\subsection{Alienación y desmitificación}

En esta novela el protagonista Alvaro Mendiola presenta una serie de afinidades biográficas que nos hacen pensar en el mismo Goytisolo: nacido en 1931, en Barcelona, de familia burguesa con antepasados en Cuba. Durante la guerra civil la madre de Goytisolo murió en Barcelona en un bombardeo de la ciudad. Refugiada su familia en una casa de campo durante la guerra, después él estudió en un colegio privado y en la Universidad de Barcelona, facultad de Derecho. En su obra Coto vedado, Goytisolo cuenta sus experiencias de estudiante en la 
universidad, sus amistades, sus comienzos de joven literato y sus primeras actividades políticas contra el régimen franquista ${ }^{(3)}$. Posteriormente, en 1956 marchó a París y allí se estableció. Se dedicó a la literatura y era asesor literario de Editions Gallimard. En París conoció a muchos intelectuales españoles exiliados, literatos y autores famosos, sobre todo hispanoamericanos: Cortázar, García Márquez, Vargas Llosa, Fuentes, Donoso, Sarduy, etc. Sus actividades en París, sus viajes a URSS y Cuba, su vida compartida durante 22 años y su matrimonio con Monique Lange en 1978, su establecimiento posterior en Marrakech, lo cuenta Goytisolo detalladamente en su obra autobiográfica En los reinos de taifa ${ }^{(4)}$. Fue una época muy importante y está muy bien reflejada novelísticamente en Señas de identidad, capítulos IV, V, VI y VII. Como vemos, hay datos biográficos similares entre Álvaro Mendiola y Juan Goytisolo. Hay también parecidos psicológicos: carácter reservado, tendencias homosexuales, desapego y confrontaciones familiares, contradicciones entre su formación éticoacadémica y sus apetencias personales, diferencia de creencias religiosas y políticas entre el protagonista/escritor y su familia, falta de integración en la tradición cultural del país, etc. Sobre todo, Álvaro (¿como Goytisolo?) se siente alienado.

Es precisamente la alienación una característica de Álvaro Mendiola. En la psicosociología moderna, la alienación es el estado de una persona que se siente extraña a sí misma, que no es capaz de realizarse en las circunstancias socio-históricas en las que vive. Así Álvaro, que había salido de España, no se ha encontrado a sí mismo en el ambiente parisino donde está, aunque tenía más libertad y autonomía. Ahora ha vuelto a España para tratar de encontrar sus raíces, pero tampoco las halla. Su estancia en Barcelona, sus recuerdos, todos sus esfuerzos por reconstruir y entender su pasado y la historia de su país, están encaminados a buscar su identidad, como dice Ramón Buckley: "En esta novela el autor no está efectuando sólo un ejercicio literario, sino una necesidad vital: hallar la justificación de toda su vida, las señas de identidad que le permitan reconocerse a sí mismo y 
vivir en sociedad"(5). Ese peregrinar de Álvaro por diversas etapas y lugares de la historia actual de España, le lleva a la conclusión de que ha perdido su idiosincrasia y su pertenencia a una familia, a una patria, a un grupo social. José Ortega, en su excelente análisis de Señas de identidad dice que la alienación es el tema central de esta novela: alienación subjetiva, o extrañamiento de sí mismo; y alienación interpersonal, es decir, incomunicación y ruptura con la familia, amigos, compañeros, etc., todas las personas que nos ayudan a tener una personalidad equilibrada ${ }^{(6)}$. Así, por sentirse sin identificación consigo mismo y con los demás, Álvaro tiene miedo de ser olvidado, de desaparecer sin dejar huella, como los caídos de la guerra civil. El teme morir sin haber legado a la posteridad nada válido: "Enfrentado al desastre irreparable de una muerte que desde el síncope del boulevard Richard Lenoir sabías cierta...sentías crecer en tu interior una violenta e inútil rebeldía contra el destino avaro que te condenaba a ti al duro olvido, hosco e insaciable"(7).

De la alienación interior y exterior en que se encuentra Álvaro, el autor pasa al análisis de la estructura social, donde se halla la causa de muchas alienaciones. Para ello, hace una revisión del pasado y el presente de España: desastre del 98, II República, guerra civil, posguerra y los años 50-60. Goytisolo desenmascara la propaganda oficial del régimen (paz, progreso, trabajo, armonía social) contraponiendo la situación real del sureste español (cap.III y IV), de los obreros dentro de España (cap.VII), y de los exiliados y emigrantes españoles en Europa (cap.V). Goytisolo hace esta crítica social mediante un proceso desmitificador: la paz, el orden, progreso, etc., traídos por el dictador son ficciones que la gente acepta por ignorancia y falta de comunicación con el exterior. Además desmonta con ironía los mitos de la guerra civil (cruzada), los valores eternos de España y el carácter benéfico-cultural del imperio español ya desaparecido: "Herederos ilustres de los descubridores del Pacífico y expedicionarios del Orinoco, de los guerreros invictos de México y héroes del Alto Perú, partían a la conquista y redención de la pagana, virgen e 
inexplorada Europa... portadores del bagaje espiritual e histórico de una patria...extendiendo por primera vez, tras un eclipse de varios siglos, el empleo cotidiano de la lengua de Cervantes en miles de hogares extraños"(8).

Esta desmitificación es también un modo como Álvaro trata de superar su alienación: no puede y no desea reencontrar sus raíces en una patria opresora y oprimida, en una sociedad intolerante, ni sujeto a una tradición cultural que no ha integrado a muchos compatriotas. La desmitificación es una búsqueda de la verdad. Destruyendo los mitos y revisando los errores históricos, es posible que algún día se encuentre la verdadera esencia del país, de sus gentes y de Álvaro mismo. Pero como todavía no divisa ese horizonte, Álvaro abandona con dolor el hogar patrio y rompe con sus raíces.

\section{RUPTURA DE LAZOS FAMILIARES Y PATRIÓTICOS}

\section{1. Álvaro: exilio inútil y sin sentido}

Álvaro Mendiola en 1952 se estableció en París, donde trabajaba de fotógrafo y estudiaba dirección de cine. Abandonó España porque no podía continuar viviendo en el estrecho marco de su familia burguesa y conservadora. También marchó al "exilio voluntario" porque la situación socio-política del país en la posguerra era muy difícil y el ambiente era "irrespirable" para un intelectual progresista como él. Así el núcleo de esta novela es el proceso lento e irreversible del protagonista hasta llegar a un total extrañamiento social. Álvaro no puede realizarse en la sociedad española de la que ha huido y a la que no reconoce como suya. Tampoco consigue realizarse en la sociedad francesa, que le gusta algo más, pero que igualmente no le pertenece ${ }^{(9)}$.

En el capítulo $\mathrm{V}$ de Señas de identidad, Ālvaro cuenta sus actividades en París, donde conoció y ayudó a muchos emigrantes españoles que iban allí a buscar trabajo. También se relacionó con muchos intelectuales exiliados que solían reunirse en el famoso café de madame Berger. Distingue Goytisolo entre aquellos emigrados políticos o intelectuales 3 grupos, según la época de su exilio a París. El grupo 
primero, al que Álvaro pertenecía, eran intelectuales emigrados ya mediada la década de 1950. El segundo grupo eran los exiliados de los años 1944-50, huidos de la represión de la inmediata posguerra. El tercer grupo lo formaban los fugitivos excombatientes de la guerra civil, que habían tenido también problemas en Francia cuando ocurrió la ocupación del país por los nazis (simpatizantes del régimen franquista). Algunos de esos exiliados importantes (como Luis Companys, presidente de la Generalitat de Cataluña) fueron entregados por los nazis a Franco y fusilados por éste ${ }^{(10)}$.

Álvaro cuenta también con mucha ironía el cambio que se producía en los exiliados españoles en París. Al principio ellos hablaban muy bien de Francia, su cultura, sus mujeres, etc., y trataban de aprender la lengua y adaptarse a las costumbres del país. Luego iban añorando más a España y su vida familiar, y simultáneamente comenzaban a criticar a Francia, sus valores socio-culturales, su sistema laboral, etc. Finalmente, abrumados por la nostalgia, se sentían expatriados viviendo en un lugar al que no pertenecían. En el mismo capítulo $\mathrm{V}$ de esta novela Goytisolo describe también con estilo irónico las actividades políticas de los exiliados, que pensaban que el gobierno de Franco caería antes de 1960. Ellos tenían conexiones con intelectuales y activistas franceses de izquierdas, y también mantenían contactos clandestinos con opositores del régimen franquista que estaban en España. Los exiliados españoles en París tenían sus tertulias organizadas; Alvaro cuenta los intentos frustrados de formar una Agrupación Nacional de Intelectuales en el Exilio con el fin de publicar una revista de diálogo sobre las corrientes políticas y artísticas modernas. Poco a poco la indolencia y la fatiga hacían que esos proyectos muriesen sin haberse realizado. Además, hacia 1960 en Francia había disminuido el interés por España, porque había otros conflictos más acuciantes (guerra fría, Europa del Este, Corea, Vietnam, Argelia, etc.). Así, la desidia interior de los exiliados y la falta de apoyo exterior hicieron que aquellas actividades políticoliterarias terminaran en un fracaso. Personalmente para Álvaro el 
exilio en París también fue haciéndose una aventura inútil e irreversible: "Lentamente, conforme se rompían las raíces que lo ligaban a la infancia y a la tierra, Álvaro había sentido formarse sobre su piel un duro caparazón de escamas: la conciencia de la inutilidad del exilio y, de modo simultáneo, la imposibilidad del retorno"(11).

Pienso que aquí el autor hace una crítica demasiado severa sobre la experiencia del exilio de Álvaro (Goytisolo) y tantos otros intelectuales españoles en París. Es cierto que no pudieron forzar grandes cambios en el gobierno franquista; tampoco estaban en condiciones de hacerlo, sobre todo cuando por su anticomunismo el régimen de Franco fue más apoyado por EE.UU. y otros países occidentales a partir de 1953. Pero aquellos exiliados españoles fueron una inspiración democrática y una referencia progresista para otros activistas e intelectuales que luchaban dentro de España. Además la presión política y la vigilancia diplomática de Francia y otros países sobre el régimen franquista favorecieron una progresiva apertura sociocultural en los años 60 .

\section{2. Álvaro apátrida: aislamiento y auto-destierro}

Al final de Señas de identidad, Álvaro llega a la conclusión de que ya no puede volver a España porque no siente nada en común con su país ni sus conciudadanos. Rotos los lazos familiares, sólo le quedaban algunos antiguos amigos de universidad y algún conocido de cuando en 1958 fue con Dolores a rodar en Murcia un documental sobre la emigración. A partir de su exilio, los lazos vitales con su patria se habían debilitado. Ahora en agosto de 1963, al final de su dolorosa búsqueda de identidad, Álvaro comprende que su trayectoria es diferente de la de España: "A raíz de tu voluntaria expatriación a París y tu existencia errabunda en Europa, la comunión anterior se había desvanecido y, extirpado tú del solar ingrato, tu aventura propia y la de tu patria habían tomado rumbos divergentes: por un lado ibas tú, rotos los vínculos que te ligaron antaño a la tribu; por otro aquélla con el grupo de tus amigos que persistían en transformarla"(12). 
En el capítulo VIII, último de esta novela, Álvaro desde Montjuich observa con un telescopio de turistas el panorama de su ciudad natal, Barcelona. Es la última oportunidad de reencontrar sus raíces. Este capitulo son 22 páginas extraordinarias, modelo de literatura experimental; pero sobre todo son una confesión sincera y sentida de la incapacidad de Álvaro para conectar y reintegrarse en su cuna de origen. Son frases sin puntuación, parecen un poema caótico y obsesivo que refleja muy bien el estado interior de Álvaro. En Montjuich él repasa la historia de la ciudad, recuerda a su familia en Cuba, se mezcla con los turistas, recorre el antiguo castillo, escenario de muchas torturas y ejecuciones durante la guerra y la posguerra (aquí fusilaron a Companys, dice). Al final, en un espléndido y delirante monólogo interior, Álvaro, "cansado, enfermo, al borde del suicidio", decide separarse de su patria, a la que están oprimiendo los líderes del régimen franquista, que cambiaban la interpretación de la historia y la guerra civil. El se siente ajeno al pasado de España, porque de ese pasado "no brotaba ningún presente limpio". Después Álvaro piensa que su nacimiento entre los españoles ha sido inútil; ya sólo le une a España la bella lengua que está "mancillada por sofismas y mentiras". Por eso es mejor "vivir entre extranjeros que se expresan en idioma extraño". Finalmente decide callar, cerrar la boca y no prolongar "la farsa irrisoria del intelectual que cree sufrir por el país y sus hombres". En ese momento, al final de la novela, como al principio de su autorreflexión, se oye de nuevo el mensaje de las "Voces" (su conciencia histórica y familiar) que se ensañan con él y le dicen: "Reflexiona todavía estás a tiempo-nuestra firmeza es inconmovible ningún esfuerzo tuyo logrará socavarla-somos piedra y piedra permaneceremos-no te empecines más márchate fuera-mira hacia otros horizontes danos la espalda-olvídate de nosotros y te olvidaremos-tu pasión fue un error-repáralo"(13).

Álvaro fracasa en la búsqueda de su identidad y en la indagación sobre sus raíces familiares, patrióticas y sociales. Solamente le quedan, además del silencio "oral", la posibilidad y el deber de "dejar 
constancia de cuanto ocurrió en este tiempo", para que las futuras generaciones sepan la verdad del país y los hechos contra los que Álvaro se rebeló. Este monólogo interior está muy bien logrado y se parece al monólogo interior de Pedro que cierra la novela Tiempo de silencio. Cuando ya no se puede hablar, sólo puede haber soliloquios. Álvaro y Pedro se ven reducidos al silencio, están frustrados, pero denuncian la situación del país. Las dos novelas indagan los fallos de la sociedad española, haciendo una revisión histórica y social. Ambas novelas están narradas desde la subjetividad del individuo y ambas intentan no sólo la solución de un problema personal, sino la reconstrucción cultural del pueblo español ${ }^{(14)}$.

A partir de aquí, Álvaro se recluye en un aislamiento deliberado y se impone un auto-destierro definitivo, que no es ya solamente un exilio temporal. Piensa que le queda poco de vida y quiere terminarla fuera del país. Aquí vemos también el carácter autobiográfico de esta novela. Goytisolo desde 1956 vive fuera de España, ahora en Marrakech. El se considera un español auto-desterrado y dice que gracias a eso ha podido escribir ciertas obras, y que no todas las cosas de España son reprobables: "Es un hecho que mi situación de "self-banished Spaniard" me ha hecho interesarme por autores como Blanco, Cernuda, etc... Toda creación literaria no es posible sin un mínimo de circunstancias favorables y cuando el escritor no encuentra estas circunstancias su deber es ir a otro país, pues de otro modo su obra no existiría... Aborrezco una cierta imagen de España que me ha marcado profundamente; pero este aborrecimiento no se extiende a la tradición progresiva española ni a una serie de elementos de nuestra cultura con los que me siento profundamente ligado"(15).

\section{REVISIÓN CULTURAL Y NUEVA FORMA LITERARIA}

\subsection{Fracaso de Álvaro: quiebra socio-cultural del país}

En Señas de identidad Goytisolo no sólo narra la historia de Álvaro y su búsqueda de raíces. Junto con el fracaso del protagonista, el autor ofrece una visión de la realidad española de los años 50-60 que arroja 
un balance negativo. Había opresión política y policial, pobreza económica, bajo nivel cultural, falta de contacto con el exterior, censura muy severa, falta de libertad de expresión y asociación, etc. En los años 60 mejoró la economía, pero otros fallos continuaron. Goytisolo dice que esos problemas no se debían sólo al régimen político y las circunstancias externas. En la novela experimental de enfoque subjetivo y dialéctico, como Señas de identidad, los problemas sociales no dependen solamente de las condiciones socio-políticas actuales. La historia del país, la cultura y el talante del pueblo influyen desde dentro en las personas y producen esos efectos malos: "El reino de los Veinticinco Años de Paz era sólo el fruto visible de una subterránea labor de generaciones consagradas a la noble misión de mantener la rígida inmovilidad de los principios... en aquel verano de 1963 tu patria se había convertido en un país de treinta y pico millones de policías no uniformados"(16). Así dice Goytisolo que la intolerancia y el egocentrismo del pueblo español se deben al hecho de que todos son intolerantes: lo han aprendido del sistema y lo han incorporado a su código de comportamiento. Las rencillas y las guerras tienen profundas raíces en la historia del país, que hay que corregir. En Señas de identidad Goytisolo señala acertadamente que tanto la burguesía como el proletariado, los republicanos y los franquistas, la derecha y la izquierda, militares y civiles, todos vivían en una cultura de desconfianza y vigilancia mutuas. En esto es bastante imparcial; todos son culpables: "Siendo niño habías asistido sin comprender al espectáculo de la lucha demente y fratricida, aterrado primero por los crímenes de los unos, indignado más tarde por aquéllos que realizaran otros... todos obedecían a las leyes de un mismo ciclo clínico en el que al frenesí y desatino de la crisis, suceden largos períodos de calma, embrutecimiento y modorra" (17).

Para superar esos "ciclos de desatino", para que no se repitan los errores del pasado (que el régimen franquista enmascaraba mediante mitos histórico-culturales), hay que desmitificar la cultura del país. Esa labor, que en la literatura española comenzó Martín-Santos con Tiempo 
de silencio, la han continuado otros novelistas del "medio siglo". Goytisolo, en Señas de identidad y sus novelas posteriores, es el literato que más decididamente ha seguido ese camino de la desmitificación cultural. Ha desmontado mitos y valores de la llamada "España sagrada" (reconquista, colonización americana, imperio, reserva espiritual de occidente, cruzada, lengua, toros, flamenco, etc.), y lo ha hecho con una narrativa, una técnica y un lenguaje radicalmente nuevos. Esta novela es el comienzo de ese proyecto: un autoanalisis nacional que parte de una desmitificación histórico-cultural y realiza una vasta tarea revisionista. Goytisolo, a través de la literatura, lleva a cabo una inmensa obra destructora y constructiva al mismo tiempo: limpiar la hojarasca histórica para que aparezcan las raíces ${ }^{(18)}$.

\subsection{Nuevo "discurso" y forma literaria}

Goytisolo, como Álvaro Mendiola al no reencontrar sus raíces ni su identidad, hace un cambio radical en su vida. Álvaro, después del ataque de corazón, se siente nacido de nuevo: "En aquel hospital anónimo habías vuelto a la vida horro de pasado como de futuro, extraño y ajeno a ti mismo, dúctil, maleable, sin patria, sin hogar, sin amigos, puro presente incierto, nacido a tus treinta y dos años, Álvaro Mendiola a secas, sin señas de identidad"(19). Como Álvaro emprende una nueva etapa vital, así Goytisolo comienza también un nuevo ciclo en su vida literaria. La crítica social objetiva o subjetiva tenía unos límites impuestos por el lenguaje usado. Después de Señas de identidad ese lenguaje se transforma también y la desmitificación se hace más intensa, sin sujeción a los lazos del idioma. Goytisolo (siguiendo a Benveniste) llama a eso un cambio de la "historia" al "discurso". La escritura tradicional se hace contando historias con un lenguaje narrativo convencional. Para hacer una revisión cultural desmitificadora, hay que superar ese lenguaje y las normas gramaticales estrictas; hay que manifestar la interioridad directamente, como en un constante monólogo. Eso es lo que ha hecho Goytisolo en el último capítulo de Señas de identidad, que abre el camino a sus novelas 
posteriores Reivindicación del Conde don Julián (1970), Juan sin Tierra (1975) y Makbara (1980). Dice él mismo: "Señas es un híbrido de historia y discurso. En Don Julián el texto tiene la verosimilitud de la comunicación puesto que todo es un pseudo-diálogo entre un narrador que habla a un personaje...hay que hacer una obra que sea a la vez crítica y creación, literatura y discurso sobre la literatura"(20).

En estas 3 últimas obras Goytisolo hace una crítica desmitificadora de la historia de España, de la cultura occidental, de las normas de conducta ética aceptadas en la tradición occidental, de las convenciones sociales, sexuales y burocráticas de la civilización actual, etc. Es una crítica global del pensamiento occidental y ello incluye una revisión del lenguaje y un cambio de la forma literaria de la narrativa tradicional. No hay personajes, ni acción desarrollada, ni argumento. Sólo hay un "discurso" o relato puro que un pseudo-narrador hace a un personaje imaginario; el lector es simplemente testigo indirecto de ese monólogo escrito con una puntuación muy original. Estas 3 novelas de Goytisolo son una superación de la novela tradicional, un mensaje directo del autor y un diálogo con otras obras literarias al estilo de Cervantes. A la vez son una revisión crítica de muchos mitos culturales no sólo de España, sino de toda la civilización occidental. Técnicamente lo más notable de las 3 novelas es la desaparición progresiva del narrador. Así el texto sin pronombres personales cambia constantemente su realidad y el lector tiene que afrontarlo directamente sin olvidar los hechos histórico-culturales que allí se critican ${ }^{(21)}$.

\section{CONCLUSIÓN}

Señas de identidad es una de las novelas más importantes de la posguerra española y plantea cuestiones muy serias sobre la realidad socio-cultural de España en el siglo XX. La crisis de identidad, alienación y desarraigo de Álvaro Mendiola son un problema generacional muy grave que afectó a muchos jóvenes españoles que no podían identificarse con su patria tal como estaba entonces. Esta novela trata de la problemática total de la sociedad española. Ese es su 
mayor mérito: hace una revisión crítica de toda la sociedad, no sólo de una parte o grupo de ella. Es una novela global de problemática real y concreta, vista a través de la subjetividad del protagonista. Es una catarsis de todo el pueblo español. Como novela "experimental" de excelente técnica, Señas de identidad es una obra clave en la narrativa española actual y el comienzo de una nueva etapa en la producción literaria de su autor. Como él mismo reconoce, en esta novela la excesiva dependencia del "esquema formal" quizá haya impedido una manifestación más sincera de la interioridad del narrador ${ }^{(22)}$.

A veces esta novela da la impresión de desorden caótico. Eso es intencionado y refleja la situación anímica de Álvaro en unos días de reflexión febril para recuperar su identidad. Pero todos los detalles, tiempos y lugares están bien conjuntados. Pienso que a veces Goytisolo exagera en su crítica de la sociedad española, de los exiliados, emigrantes, etc., y la angustia de Álvaro resulta demasiado dramática. Sin embargo su intento desmitificador es correcto y no es simplista. La relación del hombre con su pasado histórico y su entorno cultural es muy compleja; por ello las soluciones no son puramente económicas o políticas. Hacen falta una desmitificación y revisión cultural profundas que nos hagan ver las causas de los problemas y sus posibles remedios sociales. Además para hacer esa desmitificación son necesarios un lenguaje y una forma literaria nuevos. En conjunto, esta obra es pesimista, pero no nihilista. Álvaro abandona España, pero ésta puede regenerarse algún día, aunque él no consiga verlo: "Triste pueblo, patria triste, ¿qué psicoanálisis puede recobrarte? Para ti nunca pasan días y tus hijos se suceden en tu regazo inútiles frente a tu inercia, tu terquedad, tu locura. ¿Cambiarás algún día? Quizá sí (te decías), cuando tus huesos (los tuyos) fertilicen tu suelo (oh, patria) y otros hombres mejores (hoy niños todavía) aplaquen con su ofrenda el afán imposible que preside tu sino. Muerto tú (te decías), ¿a quién corresponderá contarlo?”(23). 


\section{NOTAS}

(Para la referencia completa de las obras citadas, véase la BIBLIOGRAFÍA).

(1) J. Ortega, op. cit., pp. 63-64.

(2) J. Goytisolo, Señas de identidad, Narrativa Mondadori, Madrid, 1991, pp. 128 129. Cf. también pp. 102-104.

(3) Cf. J. Goytisolo, Coto vedado, Seix Barral, Barcelona, 1986, pp. 10-24, 61-175.

(4) Cf. J. Goytisolo, En los reinos de taifa, Seix Barral, Barcelona, 1986, pp. 52. 244, 296-306.

(5) R. Buckley, op. cit., p. 211. Cf. también p. 214 (objetivismo y lirismo).

(6) Cf. J. Ortega, op. cit., pp. 33-35, 39-46.

(7) Señas de identidad, p. 322. Cf. también pp. 89, 104, 308.

(8) Ibid., pp. 197-198. Cf. también pp. 308-309.

(9) Cf. S. Sanz Villanueva, op. cit., pp. 445-449.

(10) Cf. Señas de identidad, pp. 199-200, 204-208, 343-344.

(11) Ibid., p. 214. Cf. también pp. 212-213, 310-311.

(12) Ibid., p. 133. Cf. también p. 165.

(13) Ibid., p. 349. Cf. también pp. 13-14, 346-348; G. Sobejano, op. cit., pp. 82-83.

(14) Cf. S. Sanz, op. cit., p. 453. Para cotejar las 2 obras, véase también mi artículo Tiempo de silencio: realismo dialéctico y crítica histórico-social, HISPANICA 43 (1999), pp. 135-148.

(15) J. A. Hernández, op. cit., pp. 351-352. Cf. también C. Molina, op. cit., p. 4.

(16) Señas de identidad, p. 189. Cf. también p. 233.

(17) Ibid., p. 129. Cf. también P. Gil Casado, op. cit., pp. 496-498.

(18) Cf. F. Morán, op. cit., p. 380 (aquí expone ese autoanálisis revisionista).

(19) Señas de identidad, p. 303. Cf. también pp. 51-52.

(20) J. A. Hernández, op. cit. p. 342 . En p. 341 cita a Benveniste: histoire-discours.

(21) Cf. M. Bieder, op. cit., pp. 92-96; C. Fuentes, op. cit., pp. 80-82.

(22) Cf. J. Goytisolo, En los reinos de taifa. p. 230 (la considera un híbrido).

(23) Señas de identidad, pp. 189-190.

\section{BIBLIOGRAFÍA}

BIEDER, M. (1981): De Señas de identidad a Makbara. Estrategia narrativa en las novelas de Juan Goytisolo, Revista Iberoamericana, 116-117, pp. 89-96.

BUCKLEY, R. (1973): Problemas formales en la novela española contemporánea. Barcelona, Ediciones Península, 2a. ed.

FUENTES, C. (1969): La nueva novela hispanoamericana, México, Joaquín Mortiz. 
GIL, P. (1975): La novela social española (1920-1971), Barcelona, Seix Barral.

HERNÁNDEZ, J. (1976): Entrevista a Juan Goytisolo-1975, Modern Language Notes, 91-2, pp. 337-355.

MOLINA, C.-SUÑEN, L. (1977): Juan Goytisolo o la heterodoxia consciente, Insula, 367, pp. 4-12.

MORAN, F. (1971): Novela y semidesarrollo, Madrid, Taurus.

ORTEGA, J. (1972): Juan Goytisolo. Alienación y agresión en Señas de identidad y Reivindicación del Conde don Julián, New York, Eliseo Torres.

SANZ, S. (1980): Historia de la novela social española I, Madrid, Alhambra.

SOBEJANO, G. (1981): Valores figurativos y compositivos de la soledad en la novela de Juan Goytisolo, Revista Iberoamericana, 116-117, pp. 81-88. 


\section{〈Resumen〉}

\section{“Señas de identidad": desarraigo alienante y revisión cultural}

\section{Ceferino PUEBLA PEDROSA}

Señas de identidad (1966), de Juan Goytisolo, es una de las obras más importantes de la novelística española en la segunda mitad del siglo XX. Es una novela "experimental" con variadas innovaciones técnicas: saltos temporales con cambios bruscos de escenario, diversos narradores, monólogo interior, textos periodísticos, informes de la policía, testimonios autobiográficos, párrafos sin puntuación, diálogos en francés y otras lenguas, etc. Además hay un desdoblamiento del narrador autobiográfico que suele contar sus experiencias en la forma de un "tú autorreflexivo". Es una novela de protagonista individual, que sufre una profunda crisis de identidad y ha vuelto a España unos días para reencontrar sus raíces y su auténtica personalidad. A la vez que cuenta la búsqueda frenética del protagonista, Goytisolo hace una crítica dura de la sociedad española de los años 50-60, una extensa revisión cultural y una revolución de la narrativa que el autor continuó decididamente en sus novelas posteriores. 